\title{
A Man and His Minnows: The Introduction of Gambusia affinis to Mandatory Palestine
}

\author{
Alina Kulman ${ }^{1}$ and Dan Tamïr ${ }^{2 *}$ \\ ${ }^{1}$ Arava Institute for Environmental Studies (AIES), Ketura, Israel, ${ }^{2}$ Department of Evolutionary Biology and Environmental \\ Studies, University of Zurich, Zurich, Switzerland
}

While the ecological aspects of aquatic introductions have been thoroughly researched, lesser attention has been given to the social, historical, cultural, and ideological contexts of such intended introductions. The introduction of Gambusia affinis to Palestine was made quickly by one person, who documented the process - and hence may serve as an excellent case study: Israel Kligler's scientific reports and personal correspondence from the late 1920s and early 1930s provide us with an opportunity to witness the thoughts and ideas behind that introduction process. We find that the swift and quick

OPEN ACCESS

Edited by:

Gertrud Haidvogl,

University of Natural Resources and

Life Sciences Vienna, Austria

Reviewed by:

Omri Tubi,

Northwestern University, United States

Martin Mahony,

University of East Anglia,

United Kingdom

Jan Peter Verhave,

Radboud University Nijmegen

Medical Centre, Netherlands

*Correspondence:

Dan Tamir

dan.tamir@uzh.ch

Specialty section:

This article was submitted to

Human-Wildlife Dynamics,

a section of the journal

Frontiers in Conservation Science

Received: 26 January 2021

Accepted: 06 January 2022

Published: 22 February 2022

Citation:

Kulman A and Tamir D (2022) A Man and His Minnows: The Introduction of

Gambusia affinis to Mandatory

Palestine.

Front. Conserv. Sci. 3:649955. doi: 10.3389/fcosc.2022.649955 introduction was facilitated by a combination of three factors: Zionist institutions' desire to test new scientific tools and methods, the colonial desire to control the environment and actively "ameliorate" it, and Kligler's close working ties with US-American institutions. We argue that histories of introductions should be regarded and analyzed by examining such technical-political conjunctures.

Keywords: mosquitofish (Gambusia affinis), Palestine (1917-1948), malaria, invasions ecology, modernism, British Empire, Zionism, technological optimism

\section{INTRODUCTION}

A tiny fish, feeding on the larvae of an insect considered a pest, was brought from the new world to the old one by scientists dedicated to improving public health, in order to help fight a debilitating disease. With all these good intentions and professional and precise conduct, what could go wrong? Many things, apparently. The exportation of Gambusia affinis (as well as some of its close relatives) from the northern shores of the Gulf of Mexico to Asia and Africa, with the aim of fighting malaria, became during the past century a textbook example of a biological invasion: it was introduced to dozens of locations, bringing the little fish to the top of global invasive species listings. Its introduction to mandatory Palestine was prompt, centralized and well documented-and hence may serve as a good case study for examining the introductions of that species.

Biological invasions pose significant direct and indirect threats to both specific other species and entire ecosystems. Invasive alien species break down bio-geographic realms, affect native species richness and abundance, increase the risk of native species extinction, affect the genetic composition of native populations, change native animal behavior, alter phylogenetic diversity across communities and modify trophic networks (Pyšek et al., 2020). They are directly associated with human diseases; indirectly they lead to substantial economic damage. It is true that humans have been moving plants and animals with them across continents and oceans for millennia, and that the shifting labels applied to alien species also emphasize the subjectivity of these labels, and the caution required in employing them, as well as their ability to shape our views of the natural world (Hall, 2017). However, the great advances in transportation and cultivation methods during 


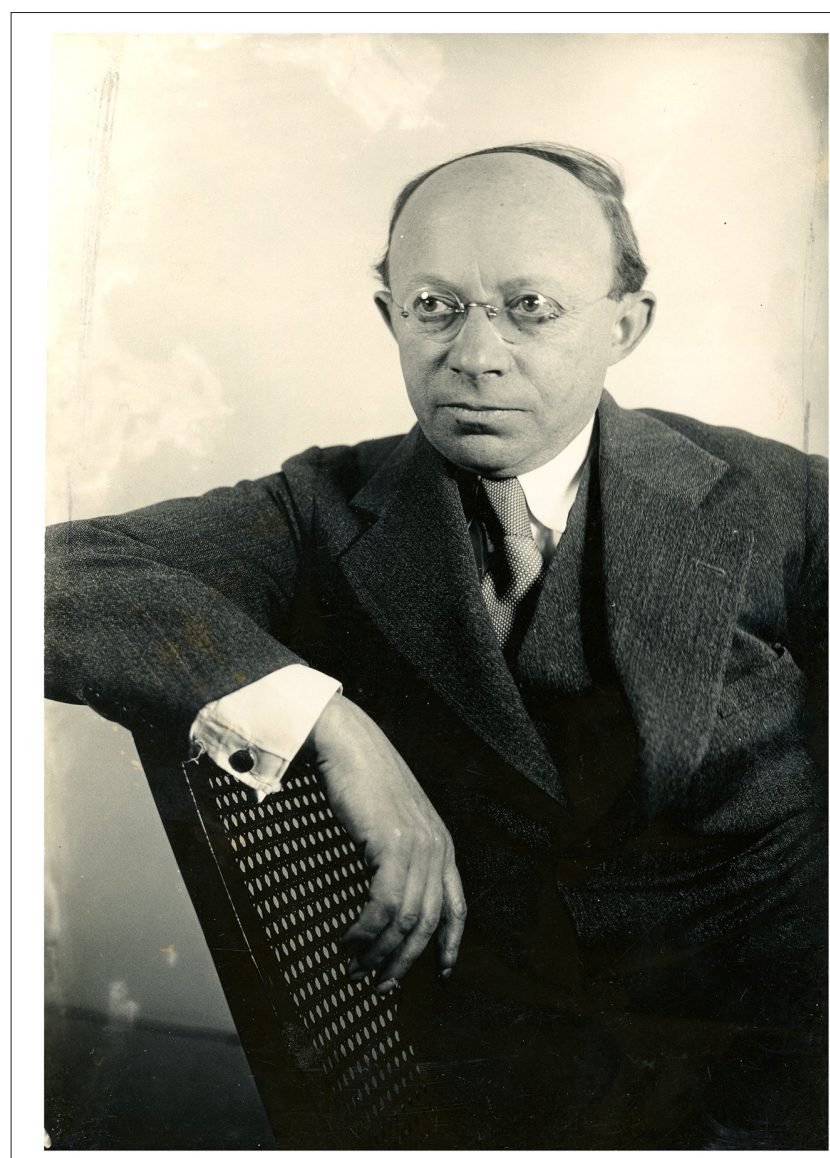

FIGURE 1 | Israel Kligler, year unknown (probably during the early 1930s). Courtesy of the Central Zionist Archives (phg/1111521).

the past century have accelerated and broadened this biological exchange tremendously, to a degree that invasive species (also referred to sometimes as "neobiotic species") have become one of the hallmarks of our era, "resetting the path of evolution" in many if not most ecosystems (Molnar et al., 2008; Williams et al., 2015).

Such invasions of plants and animals are not always the result of an intended introduction of a certain species by humans: species may be introduced by humans not aware of the introduction. Furthermore, introductions of new species into an ecosystem do not always result in full invasions, as many species do not survive in their new environments. Still, many biological invasions are the result of a deliberate human introduction of species which went out of control; the global spread of Gambusia affinis is an example of such an invasion mechanism.

Regularly featuring in lists of famous and globally spread invasive species (see e.g., Lowe et al., 2000), Gambusia affinis (alternatively named "mosquitofish" or "Western mosquitofish") is a small fish (usually not more than $6 \mathrm{~cm}$. long) native to the fresh waters of the eastern and southern United States. It has become a pest in many waterways around the world following initial introductions during the first decades of the twentieth century as a biological control of mosquitoes. Its innocuous appearance may be deceptive, since, as it eats not only mosquitoes' eggs and larvae, but also other fish and invertebrates. Studies conducted worldwide in countries where it was introduced showed how Gambusia fish endanger aquatic invertebrates, other fish, and amphibians (Pyke, 2008). Specifically in the Eastern Mediterranean, a recent survey found that more than $20 \%$ of all threatened and near threatened freshwater fish species in that region are made vulnerable by invasive alien species; again, Gambusia-be it G. affinis or its close relative $G$. holbrooki, whose impact on native fauna seems to be quite similar-is one of the first culprits named in this context (Smith et al., 2014).

The basic biological and ecological impacts of Gambusia spp. have been studied extensively; their biocontrol efficacy, translocation pathways and current distribution are also well reviewed. Relatively little analysis, however, has been dedicated to the specific historical, cultural, and ideological contexts in which its introductions were made, how it came to be used for biocontrol globally, and how attitudes about its use have diversified and shifted (Fryxell et al., 2021). Thorough evaluation of these motivations can first help us understand the human instinct to import alien species in general, potentially preventing undesired introductions in the future; in the case of Gambusia, this is not a small feature, as these fish are still being traded and introduced globally. Secondly, such evaluation may reveal unknown aspects of the relationship between the introducers and the natural surroundings of both the origin of the species and the point of introduction. Altogether, it can inform us about the manner in which scientists perceived and understood the geographical and the biological environment in which they were - and to a certain degree probably still are-acting.

Analyzing possible ideological, social, and cultural motivations for past human actions is a complicated endeavor. For this assessment, this article follows the methodology used to examine the introduction of another freshwater fish to Palestine, the European carp, Cyprinus carpio, by tracing intellectual, cultural, and ideological motives for introduction. Although the carp was introduced not to eat larvae-but rather to serve as a source of protein for the growing population-the biological and operational introduction process of these two freshwater fish is worth comparing (Tamir, 2010).

The case of the introduction of Gambusia to Palestine seems even easier to trace, as the species was initially transported by a single person, the microbiologist Israel Kligler (Figure 1). Theoretically, it is possible that Kligler wholeheartedly believed his was the first introduction of G. affinis to Palestine-and was wrong. This, however, is very unlikely: one of the reasons underpinning Kligler's local and international stand was his reputation as the "importer" of updated state-of-the-art scientific knowledge to Palestine (Zalashik and Greenberg, 2009). Previous introduction efforts made by British malariologists were well documented and mentioned only the introduction of Tilapia species (League of Nations Malaria Commission, 1925). We did not find any evidence of Gambusia spp. introductions to the Ottoman Empire: the fish was introduced to the independent parts of Greece in 1906-but very unlikely to its eastern provinces 
(Mandyla et al., 2011); the first recorded attempts to introduce Gambusia spp. to the core territories of the Ottoman Empire probably took place only in 1929 (Akder, 2010).

That way or the other, this article examines the human aspects of the introduction process, and not its biological outcomes; for the sake of the matter, the fact that Kligler and his colleagues believed theirs was a pioneering introduction is strong enough for us to relate to it as such. The introductory process is examined by analyzing Kligler's personal and professional correspondence located at the Central Zionist Archives, in addition to his published scientific and public-facing work on malaria, alongside secondary sources. While historians have documented Kligler's biography and many of his anti-malarial techniques, his importation of Gambusia has been generally overlooked. This analysis aims to understand how Kligler's motivations-explicitly stated and implicitly acted upon-for introducing Gambusia are both grounded in and revealing of his era's social paradigms (Tamir, 2010).

On the face of it, the motivation for introducing the Gambusia to mandatory Palestine is self-evident: reducing the population of anopheline mosquitoes, to curtail the incidence of malaria. But what prompted this introduction? Why did Kligler choose this method rather than another? What made him prompt and push this tool?

This paper reconstructs the cultural and ideological motives in Kligler's reasoning for introducing Gambusia to Palestine, identifying three key factors. The first key factor is practical: Kligler's relationship to Zionist circles and establishment within American scientific institutions - the ones facing malaria and the suppliers of a possible solution. The second and third factors relate to the era's ideological currents: the Zionist movement's shift from a romantic toward a pragmatic, scientific view of Palestine. After all, there were colonial efforts to modernize the country, altering its topography, fauna, and flora. We begin the story with malaria.

\section{MALARIA}

Malaria is probably the oldest and cumulatively the deadliest among the infectious diseases affecting humanity. With its origins in Africa, it traveled around the world with humans to Asia, Europe, and later the Americas. Its cause is the presence in the blood of a single-celled life form named Plasmodium; its four different species-affecting humans in various degrees of severity-are transmitted by female mosquitoes of several species of the genus Anopheles. The complex life cycle of the parasite, which requires the transition through the mosquitoes' gut and salivary glands and the human liver in order to survive and reproduce, binds together humans, plasmodia and anopheles into a triangle of closely connected organisms-an ecosystem of a kind (Webb, 2009).

Malaria may be debilitating and deadly. The connection between wetlands and marshes to malaria was known for centuries, making humans believe that its cause is the stinking odor emerging from swamps, hence its Latin name malaria, meaning "bad air"; those humans who could do it, tended to avoid moist areas and marshes during the warm seasonsthe mosquitoes' breeding period. Through eighteenth-century colonial entanglements in the New World, Europeans discovered and exported quinine, a compound extracted from the bark of a Peruvian tree, as a cure for malaria (Gachelin et al., 2017). However, treatment with quinine could not be scaled up for curing large populations affected by malaria because of its rarity and high cost, and because it does not prevent transmission of the disease (Snowden, 2003). The aforementioned infection mechanism of malaria was discovered in the late nineteenth century, and soon afterwards malariologists and state planners in affected countries, including the United States, Brazil, India, Italy, and Spain, began efforts to curtail the spread of malaria, rather than curing those infected (Gachelin et al., 2018).

By the beginning of the twentieth century, malaria was understood to be the most common disease in Palestine, and it was massively deadly. In 1922, four years after the British conquest of Palestine, $5.7 \%$ of the population suffered from malaria each month (Kligler, 1930a,b). According to some estimations, in villages like Bayt Jibrin, one out of six people died due to a malaria outbreak in the course of three months at that time (Salternik, 1978). By 1922-1923 two species of malaria parasites were prevalent in Palestine: Plasmodium vivax, causing benign but debilitating fevers in spring and summer; $P$. falciparum, with its more dangerous complications, peaked in summer and autumn. In 1925 almost $70 \%$ of malaria cases were caused by P. vivax (League of Nations Malaria Commission, 1925). Even if these estimations are exaggerated, it is clear that malaria posed a considerable challenge to public health.

The efforts to eliminate malaria in Palestine under the British Mandate involved hundreds of distinct yet interconnected initiatives in urban and rural areas alike. While the use of quinine was not unknown, these efforts mainly focused on eliminating breeding grounds for infected mosquitoes, by draining swamps and turning wetlands into "dry" agricultural land (Sufian, 2007:93). Parallel to this, efforts were made to fight mosquitoesmostly in their larval stage. This was done by chemical methods and by predation by fish. These combined efforts proved successful: after three years of intensive anti-malaria efforts, the Malaria Commission of the League of Nations commented on the success of malaria elimination in Palestine that "the work done in Palestine destroyed pessimism, [and] raised hopes" (Alexander, 2018). These hopes were not unrealistic: within less than three 3 decades, the disease-although not its vector-was entirely eradicated from the country (Sufian, 2007:89).

The first attempts at using larvae-destroying fish to combat malaria in Palestine took place already during the First World War: in July 1917, British scientists from the Society of Tropical Medicine and Hygiene brought Tilapia, a freshwater fish from Egypt, to eat mosquito larvae in pools in Shellal, Tel el Fara, and El Gamli, in areas where British troops succumbed to malaria by the scores (Austen, 1919). Zionist efforts to eliminate malaria in Palestine, part of larger statebuilding initiatives during the British Mandate, coincided with international endeavors to combat the disease. Campaigns against disease-bearing mosquitoes were initiated by both the British colonial government and private institutions. Throughout 
and in the immediate aftermath of the British Sinai and Palestine campaigns, the British army created anti-mosquito squads tasked with documenting the prevalence of malaria and destroying breeding places wherever possible near army camps (Alexander and Dunkel, 2017). After the Ottoman defeat in 1918 and the commencement of the British Mandate in 1920, Zionist resettlement agencies, including the American Jewish Joint Distribution Committee (JDC), funded and housed antimalarial campaigns that were intertwined with the Mandate's Health Department (Sufian, 2005). All of these efforts were guided and conducted by several scientists. One of them was Israel Kligler.

\section{KLIGLER}

Born in 1888 in the town of Kopychyntsi (then part of the Austro-Hungarian empire, today in Ukraine), Israel Kligler immigrated to the U.S. with his family in 1901. Kligler graduated from City College of New York in 1911, and received a $\mathrm{PhD}$ in Bacteriology, Pathology and Biochemistry from Columbia University four years later, in 1915. After a brief fellowship at Northwestern University's medical school, he worked for the Rockefeller Institute for Medical Research, conducting studies in sanitation, bacteriology, and Yellow Fever (Alexander and Greenberg, 2012). In December 1920, Kligler-by then an accomplished microbiologist-realized his Zionist aspirations by moving to Palestine (Alexander and Dunkel, 2017). A bit more than a year later, he moved to Haifa to direct the Malaria Research Unit. The organization was founded by the JDC but later became closely affiliated with the Mandate's Health Department through land concessions and coordinated initiatives (Sufian, 2005). Jewish settlements had been largely located in swampy areas, where malaria was rampant (Kligler, 1925); Kligler focused his team's research on "vector control," that is, directly targeting the mosquitoes capable of transmitting plasmodium parasites. His research indicated that mosquitoes could breed in pools of water of any size, from a large pond to a small puddle.

In 1922, the Mandate government, advised by Kligler, passed the first Public Health Anti-Malaria Ordinance. The legislation ushered in a multi-pronged campaign comprising swamp drainage, public education, and proper water treatment (Palestine Antimalarial Advisory Committee, 1922). The 1922 Ordinance indicated the government's willingness to enforce new restrictions around land use to eliminate malaria, and to support Kligler's research. After 1922, the Malaria Research Unit continued tracing patterns of Anopheles mosquitoes, conducting widespread human testing, and introducing, in 1923, a new fish species into mosquitoes' breeding places (Salternik, 1978). The strategy used here was similar to the one which prompted the use of Tilapia, with a different tactic: the introduction of Gambusia affinis, originated from the southeastern United States. Kligler placed these newcomers in canals, reservoirs, and pools in several places around the country-in Zichron and Hadera in large numbers, as well as in Jerusalem-to reduce the mosquito population (Kligler, 1930b). Kligler most probably knew about the recent introduction of Tilapia from Egypt, although by 1930 he already referred to Tilapia as a "native" fish. Apparently, the
Tilapia was not as efficient a larvae eater as initially expected. Kligler's effort differed from earlier projects in that rather than encouraging the use of local fish or transporting a regional fish across national borders, he introduced a new world species-one with potential to become invasive.

\section{A LITTLE HUNGRY FISH}

Colloquially known also as 'mosquitofish'. G. affinis is an abundant freshwater fish from its origin in the Mississippi River, successfully introduced worldwide since the beginning of the twentieth century until recent times (Pyke, 2005). Its worldwide dissemination has led to a significant body of literature on the biology and history of both G. affinis and its close biological relative, G. holbrooki-a comprehensive bibliography contains over 700 articles and 50 university theses. G. affinis has a fairly nondescript appearance- a small silver and gray minnow, usually between 1 and $5 \mathrm{~cm}$ long (Pyke, 2005). The species' strong teeth and flattened head reflect its foraging behavior: $G$. affinis obtains its necessary food and oxygen near the water's surface. It prefers warm and shallow water, and may nourish on a flexible diet: depending on its surroundings and food availability, G. affinis consumes insects, crustaceans, worms, smaller fish algae, and pertinently, mosquito larvae. G. affinis is known to be aggressive, biting and fighting smaller fish. However, they are rarely territorial, even though they are non-migratory and usually stay within a small radius of their usual place. G. affinis also has high reproductive potential-hence a single impregnated female fish, introduced into a new, suitable area, may start colonizing it (Pyke, 2005).

Current research has cast doubt over whether G. affinis is a successful antimalarial weapon. A 2017 meta-study evaluating whether the introduction of larvivorous fish reduces malaria transmission determined that due to inconsistent and limited results, "countries should not invest in fish stocking as a standalone or supplementary larval control measure in any malaria transmission areas" (Walshe et al., 2017); in other words: with all its ability to devour larvae, one cannot really count on $G$. affinis to annihilate all the larvae in its vicinity. But in 1923, when the species arrived in Palestine, scientists were highly optimistic about its ability to curtail mosquito population growth (Gachelin et al., 2018). Kligler, too, was initially certain about G. affinis' potential in Palestine, writing in 1923 that he predicted their "success" (U. S. Bureau of Fisheries, 1923); several years later he was of the opinion that the contribution of Gambusia to the overall anti-malarial campaign was partial at the best, as other measures (mostly the draining of swamps) proved more efficient (Kligler, 1930b). However, the main concern here, rather than the technical success or failure of the introduction, is the ideas and the motives which prompted it. What were the motives for the initial introduction?

\section{MOTIVES FOR INTRODUCTION}

What prompted Kligler and his associates to introduce Gambusia? On the face of it, the motivations for the introduction 
of G. affinis seem to be self-evident. First of all, Kligler was a modern, mainstream-educated scientist, with a clear desire to solve practical problems. He was working from the scientific, technical justification that larvivorous fish would be a successful antimalarial strategy. This scientific attitude went hand in hand with the Zionist ideology of that time, which favored a scientific and technocratic approach to solving environmental problems in Palestine (Tal, 2008). Additionally, Kligler was an American scientist, with strong relationships with American scientific institutions. It was only natural that he would resort to North American methods, implementing protocols used in the US, while working with organisms familiar to him and his professional circles. Finally, there was the British colonial desire to control and rationalize the environment and ameliorate living conditions of the people who live there. The ideas of "white man's burden" or a "civilisatory mission" may seem arrogant and patronizing today, and justly so. However, at the beginning of the twentieth century, these were hallmarks of colonial thought (Osborne, 2000; Tubi, 2020).

There are, however, some caveats to these straightforward explanations. A scientific bearing and a modernist approach alone cannot explain G. affinis' introduction, since there were malaria-infested locations around the world where this fish was not introduced for combating the disease. As for Kligler's rearing in the United States-G. affinis was introduced to many locations around the world beyond the reach of direct US influence; in other words: one did not have to be American in order to import that fish. As with many other environmental events, the introduction of $G$. affinis to Palestine was facilitated by a conjuncture of trends, abilities, and perceptions prevalent at the time. The following is an assessment of the various motives for the introduction, in their social historical context. It is in fact the combination of these motives that can explain the introduction process of G. affinis to mandatory Palestine.

\section{Relationship With American Institutions}

Kligler's connections as an American scientist were influential logistically and ideologically in his importation of Gambusia to Palestine. As early as 1905, Alvin Seale, an American ichthyologist, first identified Gambusia as a possible tool for combating mosquito procreation in the southern United States (Gachelin et al., 2018). After Seale's discovery, Samuel Hildebrand, an ichthyologist employed by the U.S. Bureau of Fisheries, advocated extensively and resolutely for Gambusia's dissemination in government and scientific publications. In a 1921 article for the U.S. Department of Health's journal, Hildebrand wrote that "it appears to be of great importance to distribute Gambusia to all standing and sluggish waters as far as possible" (Hildebrand, 1921). Hildebrand described a Gambusia study conducted in 1922 for the U.S. Bureau of Fisheries Bulletin: "The data obtained show beyond doubt that, were it not for the degree of control that is provided by fish, mosquitoes would become absolutely intolerable nuisances" (U. S. Bureau of Fisheries, 1922). Hildebrand's degree of certainty about Gambusia's potential, as indicated in his hyperbolic language, led to the exportation of the fish, first to Spain in
1921 (Hildebrand, 1931; Vannini et al., 2018). Kligler brought Gambusia to Palestine in January 1923-before it was sent to many other European countries, including notoriously malaria-infested regions such as continental Italy (in 1923) and Corsica (in 1924). Kligler also had close work connections with the Rockefeller Foundation, and the Rockefeller Institute for Medical Research, his former employer, between 1916 and 1920. The RF became Hildebrand's major international partner in sending Gambusia abroad (Gachelin et al., 2018), while Kligler's Malaria Research Unit remained deeply intertwined with the Rockefeller Foundation throughout the 1920s; the RF had meanwhile enrolled a major malaria control program in various countries and many of the Foundation's prominent members wrote and commented on Kligler's efforts in Palestine (Tubi, 2020).

Kligler's means of transferring Gambusia to Palestine further indicate his entrenchment within American institutions. In November 1922, Kligler requested "a number of top minnows" from the U.S. Bureau of Fisheries for his antimalarial work in Palestine. On December 8th that year, the bureau forwarded 200 minnows to Kligler in New York, through the Rockefeller Institute office. One month later, on January 8th, 1923, the bureau received a letter from Kligler announcing that 170 fish had survived the trip to Palestine. "I hope that we shall succeed in planting them here," Kligler wrote them, "I want to thank you again for your helpfulness and shall be pleased to inform you of our success with these minnows" (U. S. Bureau of Fisheries, 1922). Kligler's ease and speed in bringing Gambusia to Palestine reflected his status and connections as an American scientist working for an elite organization. As an American traveling back and forth between the U.S. and Palestine, he was able to bring the minnows himself, rather than relying on an external shipment.

Along with Kligler's intellectual connections within American scientific institutions, he received significant financial backing for his antimalarial work from American Zionist groups. In 1920, Louis Brandeis, American Supreme Court Justice and president of the Federation of American Zionists, visited Palestine and saw the negative effects of malaria on Jewish settlements. After returning to America in 1921, Brandeis endowed Kligler with a $\$ 10,000$ grant (equivalent to $\$ 151,000$ today) through the JDC to support experiments with anti-larval malarial control (Kligler, 1925). Kligler recognized the necessity of external funding to support Jewish settlement in Palestine. On December 8th, 1922, the same day that the Bureau of Fisheries sent Gambusia minnows to Kligler, he wrote in a letter to his wife that "without the constant flow of Zionist money, small tho [sic] it is, the community is incapable of existence at the present time" (Kligler, 1923). Kligler's financial support from American Zionist institutions was bolstered by his status as an American scientist; he was able to form relationships in America with important financial backers like Brandeis and Bernard Flexner, chairman of the JDC, and leverage those connections to support his scientific endeavors. His American connections provided him therefore with both the needed scientific knowledge and the means to implement it overseas. 


\section{Zionism as a Scientific Project}

Gambusia served as part of Kligler's scientific initiative to eliminate malaria, amid a larger trend of Zionist technological optimism. Political scientist Avner de-Shalit posits that after the first waves of Jewish immigration to Palestine, there was a shift in Zionist ideology from Romanticism toward pragmatism, due in part to European Jews' anxiety about how to survive in the new land (De-Shalit, 2007). De-Shalit identifies the transition away from prioritizing spiritual connections to the land as occurring only in the 1930s; for Kligler and his colleagues, however, the seeds of this shift were present in his antimalarial work a decade earlier. He saw his work explicitly in opposition to what he referred to as "eastern" Zionist views:

Justice Brandeis and his associates held that the reconstruction of Palestine presented a practical problem, to be dealt with practically by methods suggested by practical economics, practical sanitation, etc. The eastern view was that the reconstruction of Palestine is a semi-mystical event in which enthusiasm is more important than hard sense and in which things will somehow fashion themselves provided we do not tamper in any way with the immolating and mystic devotion of the people engaged in the holy work (Kligler, 1925).

Born in the same part of the world as the bearers of this "eastern view" but raised and educated in New York, Kligler developed a professional stance with Western rationality and practicality that took a scientific approach to environmental transformation. This rationality affirmed the need for Zionists to systematically take action to make the land more hospitable for Jewish settlement. When introducing Gambusia, Kligler conducted significant testing in laboratories to find the ideal conditions for the fish to serve as a larvae destroyer. Initially, these tests were unsuccessful (Kligler and Weitzman, 1924). Kligler wrote in a letter to his wife around that time that "things at the lab seemed to go wrong. Everything seemed in an awful mess" (Kligler, 1923). Nonetheless, Kligler continued experimenting around the country in ponds and canals, and finally identified what he saw as optimal conditions for the fish to serve as larvae destroyer: breeding in moderately clean standing water (Kligler, 1930b). Kligler's experimentation necessarily altered the ecosystems in those bodies of water. Unlike other, mystical pioneers led by sentiments and sublime feelings (Neumann, 2011), he viewed malaria - and the land it infested-as a "practical" which meant that he did not interpret the land of Palestine to be holy and thus untouchable, requiring the self-sacrifice of the individual.

For Kligler, eliminating malaria called for implementing every potentially viable solution, including the introduction of a foreign fish. Kligler, as well as other Zionist scientists working on agricultural and industrial development, saw Palestine as a site of experimentation. As Tamir (2010) showed, Palestine at the time served as fertile ground for trying out different tactics without extensive concern for the permanent consequences of their actions on ecosystems or on the environment. Tubi (2020) goes even further, arguing that malaria's devastating effects on colonial settlement fostered settler state-building, since coping with malaria necessitated the creation of such sociotechnical arrangements, marshaled by national medical and political institutions. This modern technical-scientific desire to experiment and try novelties went hand in hand with the colonial desire to organize, order, and bring under control.

\section{Colonial Control of the Environment}

Human modification of "nature" and the alteration of entire ecosystems is not new. People have sought ways to control their surroundings through modification since time immemorial. Modern European imperial and colonial thought, however, led to new methods of state control for systematically transforming inhospitable environments. Part of paving the path to our contemporary Anthropocene, modern colonial and imperial ecosystem changes differed from past environmental interventions in three aspects. First, they were made on an unprecedented scale, with global impacts. Secondly, they were carried out in close cooperation with scientific cadres and institutions. Finally, they were implemented, by definition, in "foreign" lands, hence supplying yet another degree of alienation between humans and their environments.

European imperial powers often sought to transform colonized landscapes with 'rational' land management that would improve productiveness of resource extraction and agricultural output with little regard for environmental degradation (Ross, 2017). In the nineteenth and twentieth centuries, European powers carried out large-scale engineering projects in their colonies to foster their land exploitation, including laying out transcontinental railroads, telegraph systems, irrigation dams and canals (Arnold, 2005). Palestine made no exception to this rule: the British Mandate government conducted or facilitated the construction of large-scale projects in the name of improving the landscape. In the context of wetlands, these included, inter alia, dams to support water-intensive agriculture, land reclamation and the construction of hydroelectric power stations (Broich, 2013; Shamir, 2013).

In the case of malaria, these large-scale transformations occurred in the aquatic landscape mostly through swamp drainage. The antimalarial efforts were inextricably linked with nationalist ideas of expanding Jewish settlement, as their Zionist proponents touted often in religious terms how these efforts would "facilitate the redemption" of the land and of the Jewish people (Sufian, 2007; Neumann, 2011). Kligler, however, generally opposed to these large-scale engineering efforts, as he believed them to be ineffective and costly (Kligler, 1925). Even so, his preferred method of malaria elimination-vector control by chemical substances and anti-larval strategies, including spraying of water bodies with larvicides and the introduction of Tilapia and Gambusia-was a form of environmental control. Kligler's introduction of a new species interrupted and changed the ecosystems and environments of reservoirs, pools, and canals all over the country, with what he regarded as "excellent results," with no mention of the species' predation or invasive spread across fresh water in Palestine (Kligler, 1930b). Kligler wrote that he believed in an "eternal" conflict between man and nature; the introduction of G. affinis, therefore, was part of an expression of the "daily vigilance" Kligler believed was required to maintain 
human domination of nature, and Jewish settlement in a land he described as an abandoned "house in disorder" (Kligler, 1930a).

Colonial control and transformation of the environment invariably also entail control of the people who are native to that land, often without their full consent and participation. While Jewish scientists perceived themselves as scientific and rational, they often blamed Palestinian Arabs for misuse of the land and claimed that Arabs were uninterested in eliminating malaria (Sufian, 2007). As Kligler described "Arab peasants" in 1930, "the intellectual level is low, and they consider illness a decree from heaven and death the will of Allah" (Kligler, 1930b) While combating a disease like malaria required nationwide effortinfected mosquitoes did not know the difference between an Arab and a Jewish town-Kligler first concentrated on Zionist settlements. He wrote in a 1925 article, "The country was divided into 10 districts centering around the Jewish settlements. In so far as the need required and the means permitted the control was extended to the neighboring Arab settlements, with a view slowly to extend the work to cover the entire country" (Kligler 1925; emphasis added). Perhaps some of his hesitancy was due to Arab protests after 1922 against anti-malaria initiatives, including drainage projects in Nazareth and Beisan that compromised community livelihoods. Palestinian Arab activists voiced their objections directly to British authorities and undertook more dramatic actions like breaking drainage pipes (Sufian, 2007:306). Indeed, despite their presumed low intellectual level, it did not escape their knowledge that these local and regional infrastructure projects were part of a larger national one.

Available evidence indicates that Gambusia was introduced mainly in Jewish settlements (Kligler, 1930b:152). However, the human-induced proliferation of the fish spread around Palestine's connected water sources, potentially disrupting food chains in swamps where Arab Palestinians fished and raised livestock (Sufian, 2007:159; Pyke, 2008:181). Elimination of malaria in Palestine was carried out without Arab say; Jewish Zionists, allied with the Mandate Government, implemented their will and their ideas for how to best solve malaria, often regarding the Palestinian Arab population either as simply posing an obstacle to modernizing development or as negligible bystanders (Sufian, 2007:306-309). G. affinis was just one example of what that control looked like and how its impact rippled across the region.

\section{CONCLUSION}

The effects of Gambusia's introduction are still felt in Israel today, as the fish threatens to destroy-and in several cases indeed destroys-habitats of indigenous species, including the endangered fire salamander, for instance (Segev et al., 2009). And if this is not enough, the impact of fish introductions on the spread of malaria may well have been overestimated at the beginning of the twentieth century, and for a long time thereafter. While biological control of mosquito larvae using various fish species has been a common practice for decades, recent assessments cast doubt on the efficacy of this control method in reducing the rate of malaria infections. Whereas research has showed that larvivorous fish may have a small impact on mosquito larval densities, there is not enough reliable data to affirm the effects of such fish on malaria transmission; meta-analyses of field reports and research regarding the use of fish for controlling malaria brought up only slight evidence that this method works (Walshe et al., 2017; Thomas, 2018).

With that in mind, however, understanding the human motivations behind the fish's introduction may provide a context for what alternatively would have been perceived as mere hubris. Malaria did levy its toll on the local population, especially in the lowlands, but occasionally on the hilly parts of the country as well. Kligler, as a well-connected American scientist backed by high-level officials and Jewish philanthropists, believed that the lands of Palestine were neglected and in need of outside intervention. Palestine's environment seemed malleable, and its freshwater pools and canals seemed a proper canvas for scientific interventions. In this sense, setting free the first 170 minnows was a part of his larger modernization and experimentation project.

While Kligler's introduction of Gambusia to Palestine was well intentioned, there was still an element of contingency in the fish's introduction process; the introduction was enabled only thanks to a combination of factors. The British desire to control the environment, the settlers' health needs, foreign financing, speedy trans-oceanic transportation-all these were just as crucial to the success of the inroduction as the mere idea of introducing a new species.

Altogether, Kligler's efforts with Gambusia were not much different from similar efforts in other countries. His scientific optimism was not a rare thing, nor did it lack context: it mirrored that era's Zionist fervor for new technologies and innovation, as well as the common belief in colonial regimes' capacity and obligation to ameliorate living conditions in European colonies overseas. Kligler simply shared the belief prevalent among early Zionists-as well as some British colonial officersthat sophisticated technology and science could be applied to transform the Palestinian landscape and eliminate health threats (Tal, 2008; Tamir, 2010). This belief was not all wrong, as the face of the country indeed changed tremendously during the last century.

Kligler's papers, including correspondence with American agencies, are well-preserved and provide a rare opportunity to study one scientist's orchestration of the arrival of an invasive species. His actions brought on permanent change in a region's aquatic life, affecting entire ecosystems. More research into Kligler's personal and professional correspondence and progress reports located at the Central Zionist Archives in Jerusalem and the Rockefeller Archive Center in Sleepy Hollow could shed further light on the intentions, methods, and preconceptions of Kligler and his fellow malariologists, as Gambusia consumed much more than its intended meals. It is likely that Kligler did not reflect much on the long-term impact of this introduction, for two reasons. First, his interest was focused on health promotion and microbiology, rather than on the environment. Additionally, the global awareness of biological invasions-and probably even the mere perception thereof-did not materialize until the mid1950s, at the earliest: a commonly accepted "date of birth" for the field of invasion biology is the publication of Charles Elton's 
book on the topic (Elton, 1958; Lowry et al., 2013). We are always wiser in retrospect; judging past generations according to the knowledge available for us today may be sheer anachronism.

During the work on this article, in early 2020, a new biological factor abruptly entered humanity's life. Whether intended or made by mistake, the appearance of SARS-COV-2 in our daily lives and the ensuing global outbreak of COVID-19 may well be considered a biological invasion following a human introduction. This hitherto unknown disease-as well as the anticipated future arrivals of other pathogens-emphasize the need for further investigation and the drawing of lessons from historical case studies. While the COVID-19 outbreak limited our access to archival material, further investigation could uncover specific data and anecdotes from Kligler's two-year experimentation process with G. affinis and the data that underscored his perception of the species' "excellent results," despite its limited and deleterious effects. Historical case studies of introductions may provide us with vital lessons in several directions. On the one hand, the methods used against and the human perception of past diseases and their carriers may help us in facing contemporary and future medical and environmental challenges. On the other hand, these exact methods may themselves carry unanticipated and undesirable consequences. After all, the main lesson we may

\section{REFERENCES}

Akder, H. (2010). "Forgotten campaigns: a history of disease in Turkey," in Turkey's Engagement with Modernity, ed. C. Kerslake, K. Öktem, and P. Robins. (London: Palgrave Macmillan), 210-235.

Alexander, A. (2018). Fatalism and malaria elimination: a historical perspective from Palestine 100 years ago. Malaria World J. 9, 1-6.

Alexander, A., and Dunkel, F. V. (2017). Local malaria elimination: a historical perspective from palestine 100 years ago informs the current way forward in Sub- Saharan Africa. American Entomologist. 63, E1-E14. doi: $10.1093 / \mathrm{ae} / \mathrm{tm} \times 060$

Alexander, A., and Greenberg, Z. (2012). Israel Jacob Kligler: the story of a 'little big man' a giant in the field of public health in Palestine. Korot. 21, 175-206.

Arnold, D. (2005). Europe, technology, and colonialism in the 20th century. Hist. Technol. 21, 85-106. doi: 10.1080/07341510500037537

Austen, E. E. (1919). Anti-mosquito measures in Palestine during the campaigns of 1917- 1918. Transact. Soc. Tropic. Med. Hygiene. 13, 47-62. doi: 10.1016/S0035-9203(19)80006-8

Broich, J. (2013). British water policy in mandate Palestine: environmental orientalism and social transformation. Environ. Hist. 19, 255-281. doi: 10.3197/096734013X13690716950028

De-Shalit, A. (2007). From the political to the objective: the dialectics of zionism and the environment. Environ. Politics. 4, 70-87. doi: 10.1080/09644019508414183

Elton, C. S. (1958). The Ecology of Invasions by Animals and Plants. London: Methuen.

Fryxell, D. C., Moffett, E. R., Kinnison, M. T., Simon, K. S., and Palkovacs, E. P. (2021). From southern swamps to cosmopolitan model: humanity's unfinished history with mosquitofish. Fish Fisheries. 00, 1-19. doi: 10.1111/faf.12604

Gachelin, G., Garner, P., Ferroni, E., Tröhler, U., and Chalmers, I. (2017). Evaluating Cinchona bark and quinine for treating and preventing malaria. J. Roy. Soc. Med. 110, 73-82. doi: 10.1177/0141076816688411

Gachelin, G., Garner, P., Ferroni, E., Verhave, J. P., and Opinel, A. (2018). Evidence and strategies for malaria prevention and control: a historical analysis. Malaria J. 17, 1-18. doi: 10.1186/s12936-018-2244-2

Hall, M. (2017). "Invasives, aliens, and labels long forgotten: toward a semiotics of human-mediated species movement," in Human Dispersal and Species take from historical biological intervention is simple: we can hardly be too cautious with what we do.

\section{DATA AVAILABILITY STATEMENT}

The original contributions presented in the study are included in the article/supplementary material, further inquiries can be directed to the corresponding author.

\section{AUTHOR CONTRIBUTIONS}

DT conducted the initial search for the materials online and at the archives, elaborated the historical context part and co-edited the 2 nd and 3 rd drafts. AK made the advanced in-depth archival research, wrote the 1 st draft, and co-edited the 2 nd and the $3 \mathrm{rd}$ drafts. Both authors contributed to the article and approved the submitted version.

\section{FUNDING}

This work was supported by Swiss National Fund, grant CRSK1_190896: salary of DK Horizon 2020-Infravec2, grant 731060: salary of DK.
Movement: From Prehistory to the Present, eds N. Boivin, R. Crassard, and M. Petraglia (Cambridge: Cambridge University Press), 430-53.

Hildebrand, S. F. (1921). Suggestions for a broader application of Gambusia for the purpose of mosquito control in the South. Public Health Rep. 36, 1460-1461. doi: $10.2307 / 4576031$

Hildebrand, S. F. (1931). Gambusia in foreign lands. Science, New Series. 74, 655-656. doi: 10.1126/science.74.1930.655

Kligler, I. J. (1923). [Letter to Helen Kligler]. Central Zionist Archives (1612, Box 16). Jerusalem, Israel.

Kligler, I. J. (1925). The fight against Malaria. Menorah J. 11, 497-501.

Kligler, I. J. (1930a). Fighting Malaria in Palestine. Jewish Soc. Serv. Q. 20, 28-30.

Kligler, I. J. (1930b). The Epidemiology and Control of Malaria in Palestine. Chicago: University of Chicago Press.

Kligler, I. J., and Weitzman, I. (1924). Annual Report, 1923. Haifa: Department of Health Malaria Research Unit.

League of Nations Malaria Commission. (1925). Reports on the Tour of Investigation in Palestine in 1925. Geneva. [LNA, C.H./Malaria/52].

Lowe, S., Browne, M., Boudjelas, S., and Poorter, D. (2000). 100 of the World's Worst Invasive Alien Species: A selection from the Global Invasive Species Database. ISSG: Auckland.

Lowry, E., Rollinson, E. J., Laybourn, A. J., Scott, T. E., Aiello-Lammens, M. E., Gray, S. M., et al. (2013). Biological invasions: a field synopsis, systematic review, and database of the literature. Ecol. Evol. 3, 182-196. doi: $10.1002 /$ ece 3.431

Mandyla, M., Tsiamis, C., Kousounis, A., and Petridou, E. (2011). Pioneers in the anti- malaria battle in Greece (1900-1930). Gesnerus. 68, 180-197. doi: 10.1163/22977953-06802002

Molnar, J. M., Gamboa, R. L., Revenga, C., and Spalding, M. D. (2008). Assessing the global threat of invasive species to marine biodiversity. Front. Ecol. Environ. 6, 485-492. doi: 10.1890/070064

Neumann, B. (2011). Land and Desire in Early Zionism. Waltham, MA: Brandeis University Press.

Osborne, M. A. (2000). Acclimatizing the world: a history of the paradigmatic colonial science. Osiris. 15, 135-151. doi: 10.1086/649323

Palestine Antimalarial Advisory Committee. (1922). Memorandum on Public Health Ordinance No 6. Rockefeller Archive Center (Record Group 5, Series 2, Subseries 825, Box 61, Folder 398). Tarrytown, New York. 
Pyke, G. H. (2005). A Review of the Biology of Gambusia affinis and G. holbrooki. Rev. Fish Biol. Fisher. 15, 339-365. doi: 10.1007/s11160-006-6394-x

Pyke, G. H. (2008). Plague minnow or mosquito fish? a review of the biology and impacts of introduced gambusia species. Ann. Rev. Ecol. Evol. Systemat. 39, 171-191. doi: 10.1146/annurev.ecolsys.39.110707.173451

Pyšek, P., P. E., Hulme, D., Simberloff, S., Bacher, T. M., Blackburn, J. T., et al. (2020). Scientists' warning on invasive alien species. Biol. Rev. 95, 1511-1534. doi: $10.1111 /$ brv.12627

Ross, C. (2017). Ecology and Power in the Age of Empire: Europe and the Transformation of the Tropical World. Oxford: Oxford University Press.

Salternik, Z. (1978). Reminiscences of the history of malaria eradication in Palestine and Israel. Israel J. Med. Sci. 14, 16-18. doi: 10.1159/000402517

Segev, O., Mangel, M., and Blaustein, L. (2009). Deleterious effects by mosquitofish (Gambusia affinis) on the endangered fire salamander (Salamandra infraimmaculata). Anim. Conserv. 12, 29-37. doi: 10.1111/j.1469-1795.2008.00217.x

Shamir, R. (2013). Current Flow: The Electrification of Palestine. Palo Alto: Stanford University Press.

Smith, K., Barrios, V., Darwall, W., and Numa, C. (2014). The status and distribution of freshwater biodiversity in the Eastern Mediterranean. Gland, Switzerland: IUCN.

Snowden, F. M. (2003). Mosquitoes, Quinine, and the Socialism of Italian Women 1900- 1914. Past and Present. 178, 176-205. doi: 10.1093/past/178.1.176

Sufian, S. M. (2005). Re-imagining Palestine: Scientific knowledge and malaria control in mandatory Palestine. Dynamis: Acta Hispanica ad Medicinae Scientiarumque Historiam Illustrandam. 25, 351-382.

Sufian, S. M. (2007). Healing the Land and the Nation: Malaria and the Zionist Project in Palestine, 1920-1947. Chicago: University of Chicago Press.

Tal, A. (2008). Enduring Technological Optimism: Zionism's Environmental Ethic and Its Influence on Israel's Environmental History. Environ. Hist. 13, 275-305. doi: 10.1093/envhis/13.2.275

Tamir, D. (2010). Motives for Introducing Species: Palestine's Carp as a Case Study. Environ. Hist. 16, 73-95. doi: 10.3197/096734010X485300

Thomas, M. B. (2018). Biological control of human disease vectors: a perspective on challenges and opportunities. BioControl. 63, 61-69. doi: 10.1007/s10526-017-9815-y

Tubi, O. (2020). Kill me a mosquito and I will build a state: Political economy and the socio- technicalities of Jewish colonization in
Palestine, 1922-1940. Theory Soc. 50, 97-124. doi: 10.1007/s11186-020-09 402-4

U. S. Bureau of Fisheries. (1922). Mosquito-control experiments at Augusta, GA. Fisheries Serv. Bull. 91, 4.

U. S. Bureau of Fisheries. (1923). Successful delivery of Gambusia in Palestine. Fisheries Serv. Bull. 93, 3.

Vannini, A., Giacomo, B., Giulia, R., Leonardo, P., Emiliano, M., and Elena, T. (2018). Gambusia holbrooki, the 'tadpolefish': The impact of its predatory behavior on four protected species of European amphibians. Aquatic Conserv. Marine Freshwater Ecosyst. 28, 476-484. doi: 10.1002/aqc. 2880

Walshe, D. P., Garner, P., Abdel-Hamed Adeel, A. A., Pyke, G. H., and Burkot, T. R. (2017). Larvivorous fish for preventing malaria transmission. The Cochrane Database Systematic Rev. 12, 1-70. doi: 10.1002/14651858.CD008090.pub3

Webb, J. L. A. Jr. (2009). Humanity's Burden: A Global History of Malaria. Cambridge: Cambridge University Press.

Williams, M., Zalasiewicz, J., Haff, P. K., Schwägerl, C., Barnosky, A. D., and Ellis, E. C. (2015). The anthropocene biosphere. Anthropocene Rev. 2, 196-219. doi: $10.1177 / 2053019615591020$

Zalashik, R., and Greenberg, Z. (2009). The league of nations malaria commission to Palestine 1925. Qatedra. 134, 50-64.

Conflict of Interest: The authors declare that the research was conducted in the absence of any commercial or financial relationships that could be construed as a potential conflict of interest.

Publisher's Note: All claims expressed in this article are solely those of the authors and do not necessarily represent those of their affiliated organizations, or those of the publisher, the editors and the reviewers. Any product that may be evaluated in this article, or claim that may be made by its manufacturer, is not guaranteed or endorsed by the publisher.

Copyright (c) 2022 Kulman and Tamir. This is an open-access article distributed under the terms of the Creative Commons Attribution License (CC BY). The use, distribution or reproduction in other forums is permitted, provided the original author(s) and the copyright owner(s) are credited and that the original publication in this journal is cited, in accordance with accepted academic practice. No use, distribution or reproduction is permitted which does not comply with these terms. 